\title{
PARTISIPASI MASYARAKAT DALAM MENDUKUNG STRATEGI PELAYANAN DINAS PERPUSTAKAAN DAN KEARSIPAN KOTA BATU UNTUK MENINGKATKAN BUDAYA LITERASI PADA MASYARAKAT
}

\author{
Dewi Citra Larasati \& Yovita Bano Nahak \\ Program Studi Administrasi Publik, Universitas Tribhuwana Tunggadewi \\ Email : citralarasati311@gmail.com
}

\begin{abstract}
This study aims to determine how community participation in supporting the service strategy of the library and archival services in Batu City. Therefore, this study uses data obtained through words, written sources, photos through a qualitative method approach. Triangulation techniques are used as data collection techniques as well as data validity. The results of this study indicate that the community plays an active role in implementing the service strategy of the Batu City Library and Archives Service through mobile libraries, providing services at Taman Bacaan and cooperating with several communities in the Batu City community. Meanwhile, the supporting factors for the service strategy participation were shown enthusiastically from the employees and adequate service infrastructure. Meanwhile, the inhibiting factors faced are lack of human resources, delays in services and lack of awareness of the community itself about the importance of reading.
\end{abstract}

Keyword : community participation, strategy, library servece management

\begin{abstract}
Abstrak. Penelitian ini bertujuan untuk mengetahui bagaimana partisipasi masyarakat dalam mendukung strategi pelayanan dinas perpustakaan dan kearsipan Kota Batu. Oleh karena itu, penelitian ini menggunakan data yang diperoleh melalui kata-kata, sumber tertulis, foto melalui pendekatan metode kualitatif. Triangulasi teknik digunakan sebagai teknik pengumpulan data serta keabsahan data. Hasil penelitian ini menunjukkan bahwa masyarakat berperan aktif dalam melaksanakan strategi pelayanan Dinas Perpustakaan dan Kearsipan Kota Batu melalui perpustakaan keliling, mengadakan layanan di Taman Bacaan dan bekerja sama dengan beberapa komunitas yang ada di masyarakat Kota Batu. Sedangkan untuk faktor pendukung partisipasi strategi pelayanan terlihat dengan antusias dari pegawai dan sarana prasarana pelayanan yang memadai. Sedangkan untuk faktor yang menghambat yang dihadapi adalah kurangnya sumber daya manusia, keterlambatan pelayanan dan kurangnya kesadaran dari masyarakat itu sendiri akan pentingnya membaca.
\end{abstract}

Kata Kunci: partisipasi masyarakat, strategi, manajemen pelayanan perpustakaan

\section{PENDAHULUAN}

Pelayanan terhadap masyarakat merupakan rangkaian kegiatan secara sadar dimana kegiatan tersebut memiliki tujuan untuk memenuhi kebutuhan masyarakat, baik berupa pelayanan administrasi, jasa maupun barang yang diselenggarakan oleh penyelenggara layanan publik. Pelayanan publik pada dasarnya mengatur segala hal yang berhubungan dengan hajat hidup orang banyak sehingga masuk ke dalam semua aspek kehidupan. Sehingga pemberi layanan dituntut memberikan pelayanan yang terbaik kepada masyarakat. Oleh karena itu, esensi dari pelayanan publik sangat erat kaitannya dengan upaya untuk memperbaiki kapasitas dan kemampuan pemerintah terutama pemerintah daerah yang merupakan garda terdepan dalam memberikan pelayanan terhadap masyarakat (Mukarom, 2015:147-148).

Pemerintah daerah mendapatkan kewenangan untuk memberikan pelayanan kepada masyarakat karena dianggap paling mengetahui dan memahami kebutuhan masyarakatnya. Termasuk dalam menumbuhkan budaya literasi. Literasi di era virtual sangatlah penting karena 
di sekitar banyak sekali berita yang disinformasi atau bahkan bersifat hoax, sehingga dengan budaya literasi yang baik maka akan menumbuhkan minat baca yang tinggi sehingga diperoleh hasil yang maksimal dan masyarakat bisa mendapat pemahaman yang baik. Namun faktanya, budaya literasi masyarakat Indonesia masih sangatlah rendah. Hal inilah yang pada akhirnya menjadi salah satu faktor yang berperan terhadap rendahnya kualitas manusia Indonesia.

Berdasarkan Undang-Undang Republik Indonesia Nomor 43 Tahun 2007 Tentang Perpustakaan Bab 1 Pasal 1 menjelaskan bahwa perpustakaan berperan untuk menyediakan segala bentuk sarana dan prasarana masyarakat dalam belajar baik secara mandiri maupun berkelompok. Namun faktanya kebanyakan perpustakaan yang ada di daerah memiliki banyak kekurangan dan keterbatasan, seperti : sulitnya menjangkau ke tempat lokasi perpustakaan berada sehingga banyak masyarakat di daerah pedalaman tidak bisa merasakan fasilitas yang ada di perpustakaan. Selain permasalahan jarak tempuh, rendahnya minat baca juga menjadi masalah yang tak bisa dielakkan. Faktor lainnya yang menyebabkan permasalahan ini semakin parah yaitu faktor penguasaan dan pemahaman bahasa masyarakat, kemudian masih adanya budaya oral di sebagian masyarakat (menurut bahasa jawa : pitutur), harga buku yang tidak terjangkau oleh masyarakat karena jumlah penerbitan sangatlah terbatas, serta belum meratanya distribusi buku, dan tingkat "melek huruf" masih rendah.

Hal tersebut ternyata juga dialami oleh Kota Batu yang notebene merupakan kota yang maju. Rendahnya minat baca masyarakat tergolong rendah walaupun beragam fasilitas telah diupayakan oleh Pemerintahan kota Batu, pengunjung rata-rata tiap bulannya hanya ada sekitar 430 pengunjung. Rendahnya kunjungan tersebut dikarenakan berbagai faktor, antara lain karena masyarakat banyak yang tidak tahu keberadaan perpustakaan Kota Batu. Setelah pindah lokasi ke Balai Kota Among Tani. Permasalahan yang disebutkan tersebut diatas merupakan masalah yang perlu dicarikan solusinya dengan menjalankan strategi - strategi yang disesuaikan dengan kondisi yang ada. Sehingga bentuk rumusan masalah dalam penelitian ini yaitu: 1) Bagaimana partisipasi masyaakat dalam mendukung strategi yang dilaksanakan Dinas Perpustakaan dan Kearsipan Kota Batu dalam meningkatkan budaya literasi?, 2) Apa saja faktor - faktor yang berperan dalam partisipasi masyaakat dalam mendukung strategi yang dilaksanakan Dinas Perpustakaan dan Kearsipan Kota Batu?

Berdasarkan rumusan masalah tersebut, berikut ini ada beberapa teori yang bisa digunakan untuk menganalisis hasil penelitian sebagaimana berikut : Menurut Tjiptono dalam Suharman, 2017 menjelaskan bahwa strategi terdapat tiga komponen penting yaitu adanya sasaran, tujuan dan adanya cara untuk action, serta tercukupinya sumber daya yang dibutuhkan. Strategi pelayanan perpustakaan dalam meningkatkan minat baca antara lain : (1) Strategi promosi, yaitu melakukan kerjasama atau kemitraan pihak lain yang langsung berhubungan dengan para pembaca/pengguna layanan perpustakaan, (2) Strategi layanan luar biasa, yaitu cara yang dilakukan untuk memberikan beragam informasi yang dibutuhkan oleh pengunjung (3) Strategi layanan pelanggan, yaitu menawarkan pelayanan yang lebih baik dengan melakukan pemenuhan sarana dan prasarana yang ada termasuk mengalokasikan SDM untuk menciptakan pelayanan prima.

Dalam menjalankan strategi, tentunya perpustakaan juga dihadapkan dengan beberapa faktor-faktor yang mempengaruhi, antara lain: 1) minimnya jumlah pengelola perpustakaan, 2) Minimnya dana untuk perbaikan sarana dan prasara yang ada, 3) Terbatasnya jumlah buku di perpustakaan, 4) Layanan yang monoton / tidak up to date, 5) Terbatasnya ruangan yang dimiliki, 6) Terbatasnya sarana dan prasarana perpustakaan, 7) Lokasi perpustakaan yang 
kurang strategis, dan 8) Kurangnya sosialisasi terhadap masyarakat mengenai perpustakaan. Faktor tersebut di atas merupakan faktor internal yang mempengaruhi pelaksanaan strategi perpustakaan, sedangkan untuk faktor eksternal antara lain : 1) Kurangnya peran serta dari stakeholders yang ada baik pihak swasta, penerbitan dan lain lain,dan 2) Kurangnya kerjasama yang baik antar perpustakaan.Sedangkan dalam hal keberhasilan partisipasi masyarakat ditentukan oleh tiga unsur pokok, yaitu: 1) Masyarakat mempunyai kesempatan untuk ikut berperan aktif, 2) adanya kehenak masyarakat untuk turut berpartisipasi, dan 3) adanya kemampuan masyarakat untuk berpartisipasi.

\section{METODE PENELITIAN}

Peneliti sangat tertarik meneliti mengenai partisipasi masyarakat dengan menggunakan rancangan deskriptif menggunakan pendekatan kualitatif. Sumber data yang digunakan dalam penelitian ini diperoleh dari kata-kata, sumber tertulis dan foto. Dimana data diperoleh dengan teknik pengumpulan data menggunakan wawancara, observasi dan dokumentasi. Peneliti menentukan informan dengan menggunakan purposive sampling, yaitu mewawancarai pegawai perpustakaan, masyarakat Setelah memperoleh data peneliti melakukan analisis data dengan mengolah data dan kemudian disajikan. Untuk menguji tingkat kepercayaan data menggunakan triangulasi teknik.

\section{HASIL DAN PEMBAHASAN}

\section{Partisipasi Masyarakat dalam Mendukung Strategi Pelayanan yang digunakan Dinas Perpustakaan dan Kearsipan Kota Batu dalam Meningkatkan Minat Baca Masyarakat.}

Perpustakaan Kota Batu adalah Organisasi Perangkat Daerah (OPD) yang berada dibawah naungan Pemerintah Daerah Kota Batu berbentuk Dinas. Berdasarkan tugas pokok dan fungsi (tupoksi)nya dinas memiliki tugas menjalankan kebijakan kepala daerah dengan memberikan pelayanan langsung kepada masyarakat. Dinas Perpustakaan dan Kearsipan Kota Batu merupakaan OPD yang mengelola bahan-bahan pustaka, baik berupa buku-buku maupun bukan berupa buku (non book material) yang diatur secara sistematis menurut aturan tertentu sehingga dapat digunakan sebagai informasi oleh setiap pemakainya. Dinas Perpustakaan dan Kearsipan Kota Batu merupakan OPD yang diperuntukan bagi masyarakat luas sebagai sarana pembelajaran sepanjang hayat tanpa membedakan umur, jenis kelamin, suku, ras, agama dan status sosial ekonomi.

Permasalahan yang dihadapi Dinas Perpustakaan dan Kearsipan Kota Batu seperti yang telah dijelaskan sebelumnya di bagian pendahuluan adalah rendahnya minat baca masyarakat Kota Batu padahal fasilitas, sarana dan prasarana yang dimiliki oleh Dinas tersebut sangatlah memadai dan cenderung sangat baik. Oleh karena itu, disusunlah strategi jemput bola kepada masyarakat agar meningkatkan minat baca masyarakat yang ada di Kota Batu. Strategi yang dibuat oleh Dinas Perpustakaan dan Kearsipan Kota Batu tersebut juga membutuhkan partisipasi masyarakat sebagaimana berikut :

\section{a) Layanan Perpustakaan Keliling}

Strategi yang dilakukan Dinas Perpustakaan dan Kearsipan Kota Batu untuk meningkatkan minat baca masyarakat yang pertama yaitu melakukan layanan perpustakaan keliling. Layanan perpustakaan keliling ini dilakukan setiap bulan sesuai jadwal yang telah ditentukan dengan menggunakan bantuan dua armada mobil keliling yang menyebar ke area keramaian masyarakat seperti : ke sekolah-sekolah yang ada di Kota Batu, alun-alun Kota Batu, taman, mall dan spot-spot strategis di setiap desa dan kelurahan yang ada di Kota 
Batu. Hal ini bertujuan untuk mendekatkan pelayanan perpustakaan kepada masyarakat. Koleksi buku yang dibawapun beraneka ragam dan kecenderungannya adalah yang memiliki daya ketertarikan tersendiri bagi kalangan masyarakat di wilayah sekitar yang dikunjungi oleh mobil perpustakaan keliling. Partisipasi masyarakat sangat diperlukan, dalam mendukung upaya mobil keliling. Tanpa adanya minat baca yang baik, maka program layanan perpustakaan keliling ini tidak akan berjalan dengan baik.

Selain itu petugas juga memberikan sosialisasi perpustakaan melalui bentuk game dan hadiah-hadiah kecil supaya lebih menarik minat untuk datang ke perpustakaan keliling. Layanan perpustakan keliling beroperasi dengan menggunakan 2 armada mobil diantaranya mobil perpustakaan keliling beroperasi ke sokolah-sekolah pada jam istrahat dan mobil taman baca masyarakat beroperasi ke kelurahan dan desa yang ada di Kota Batu. Berikut adalah foto mobil Perpustakaan keliling milik Dinas Perpustkaan Kota Batu.

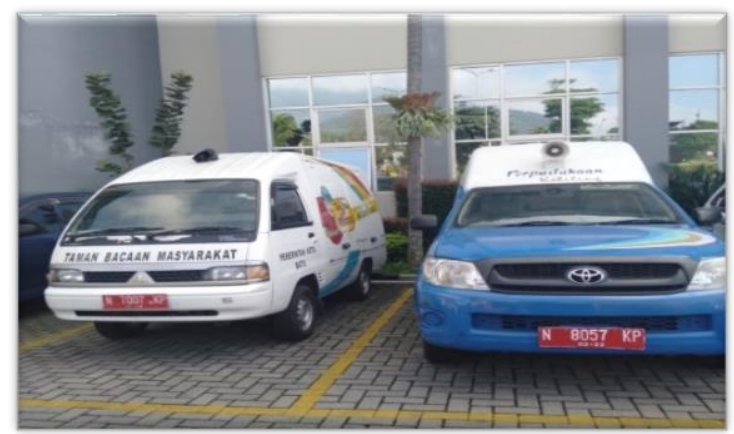

\section{Gambar 3. Mobil Keliling Perpustakaan Kota Batu}

Sumber: Dokumentasi Penelitian 2020

\section{b) Layanan di Taman Bacaan Masyarakat (TBM)}

Strategi selanjutnya yang dilakukan oleh Dinas Perpustakaan Dan Kearsipan Kota Batu yang membutuhkan partisipasi masyarakat yaitu mengadakan layanan di Taman Bacaan Masyarakat. Taman Bacaan Masyarakat ini memiliki kepengurusan tersendiri dari unsur masyarakat. Salah satu TBM yang ada di Kota Batu adalah berlokasi di Hutan Kota dengan jam pelayanan yang waktunya relatif panjang dari jam 8:00 pagi sampai jam 20.00 malam. Layanan Taman Bacaan Masyarakat ini juga bertujuan agar lebih menarik kunjungan masyarakat untuk membaca tanpa harus pergi ke Dinas Perpustakaan Dan Kearsipan Kota Batu. Pelayanan yang dilakukan ini adalah layanan terbuka sehingga masyarakat yang berkunjung bebas memilih koleksi yang dibutuhkan di Taman Baca Masyarakat tersebut. Fasilitas TBM ini tidak kalah dengan fasilitas yang dimiliki oleh Dinas Perpustakaan Dan Kearsipan Kota Batu . Istilahnya TBM ini adalah perpustakaan mini.

Pola pelayanannya pun menyerupai perpustakaan yang sesungguhnya. Adapun sarana dan prasarana pendukung yang dapat menarik kunjung untuk membaca seperti meja baca, loker, wiffi dan ACC dan terdapat juga CCTV untuk pengawasan di TBM tersebut. Apabila pengunjung telah selesai membaca koleksi buku yang tersedia, maka pengunjung bisa meletakkan buku tersebut di tempat yang yang telah disediakan agar koleksi tetap tersusun dengan rapi. Kegiatan TBM ini tidak akan berjalan dengan baik jika tidak ditunjang dengan partisipasi masyarakat dalam hal ini sebagai pengurus TBM. Pengurus TBM harus rajin membuka TBMnya supaya masyarakat rajin berkunjung dan secara aktif mempromosikan TBMnya sehingga TBM diketahui keberadaannya. Berikut ini adalah hasil observasi dan dokumentasi peneliti mengenai Taman Bacaan Masyarakat di Jalan Sultan Agung. 

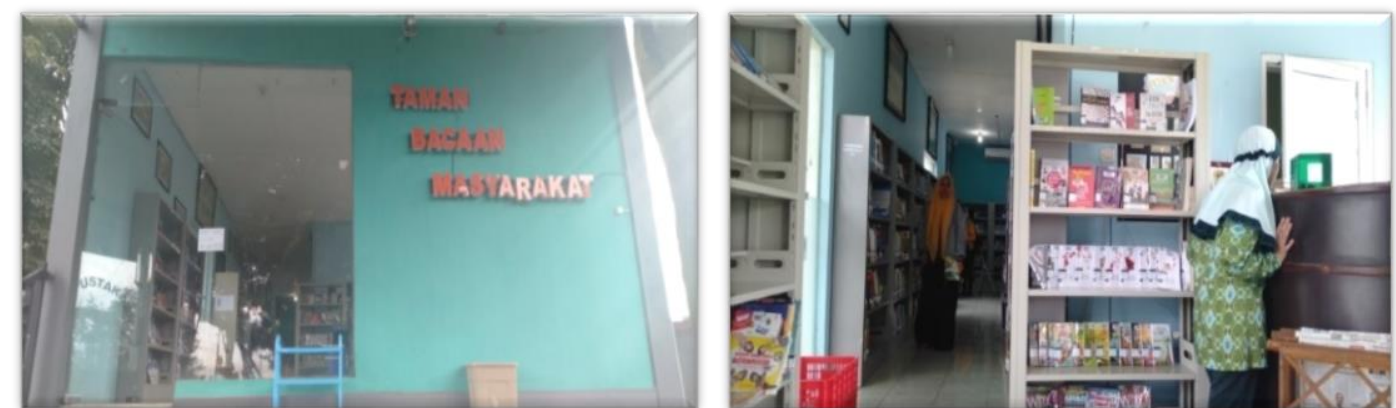

Gambar 1. Pelayanan di Taman Bacaan Masyarakat.

Sumber : Dokumentasi Penelitian, 2020

\section{c) Kerja Sama dengan Komunitas}

Selain melakukan layanan perpustakaan keliling dan menyediakan layanan di Taman Bacaan Masyarakat, Dinas Perpustakaan dan Kearsipan Kota Batu juga mengadakan kerjasama dengan komunitas yang ada di masyarakat. Strategi yang ketiga ini adalah strategi yang tidak kalah inovatif dengan strategi yang pertama dan strategi yang kedua. Strategi ini mendorong masyarakat membentuk komunitas dan didukung dengan memberikan beberapa fasilitas seperti pengadaan rak buku, serta memberikan pinjaman buku sebanyak 100 eksemplar dan akan diganti setiap dua bulan sekali. Sekitar sembilan puluh orang dari berbagai desa dan kelurahan yang ada di Kota Batu menjadi anggota komunitas pembaca masyarakat. Berikut ini adalah dokumentasi keadaan tempat baca di Kelurahan yang di pelopori oleh komunitas baca :

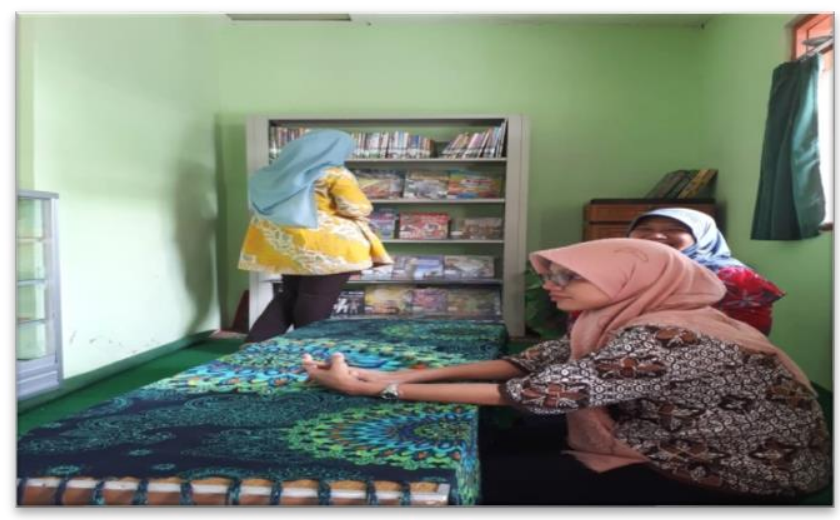

\section{Gambar 5. Kondisi Tempat Pembaca Masyarakat.}

Sumber : Dokumentasi Peneliti, 2020

Dan strategi ini sangat membantu pegawai perpustakaan, karena melalui komunitas tersebut, pengurus komunitas dengan sukarela untuk menjadi perantara perpustakaan dan masyarakat . Adapun beberapa persyaratan untuk menjadi Komunitas Pembaca Masyarakat seperti yang bisa dilihat pada gambar berikut : 


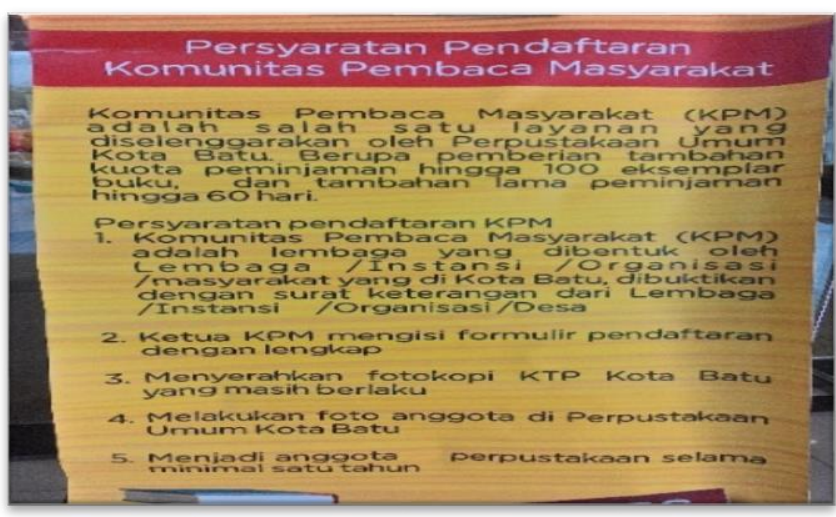

Gambar . Persyaratan Pendaftaran Komunitas Pembaca Masyarakat

Sumber : Dokumentasi Peneliti, 2020

Adapun persyaratan yang harus dipenuhi agar menjadi anggota komunitas perpustakaan tersebut adalah sebagai berikut :

1. Komunitas Pembaca Masyarakat (KPM) adalah lembaga yang dibentuk oleh Lembaga /Instansi /Organisasi /masyarakat Kota Batu, dibuktikan dengan surat keterangan dari Lembaga /Instansi /Organisasi /Desa.

2. Ketua KPM mengisi formulir pendaftaran dengan lengkap.

3. Menyerahkan fotokopi Kartu Tanda Penduduk (KTP) yang masih berlaku.

4. Melakukan foto anggotan di Perpustakaan Umum Kota Batu.

5. Menjadi anggota perpustakaan selama minimal satu tahun.

Dari ketiga strategi yang dilakukan Dinas Perpustakaan dan Kearsipan Kota Batu dalam meningkatkan minat baca masyarakat, sangat bergantung dari partisipasi aktif masyarakat juga. Istilahnya dari untuk dan oleh masyarakat. Sehingga strategi yang dilaksanakan ini dapat dilihat dari tingginya respon masyarakat melalui daftar kunjungan yang ada setiap bulannya yaitu dengan adanya peningkatan kunjungan membaca setiap bulan.

\section{Faktor - Faktor yang Berperan dalam Partisipasi Masyaakat dalam Mendukung Strategi yang Dilaksanakan Dinas Perpustakaan dan Kearsipan Kota Batu}

Partisipasi aktif dari masyarakat ini juga terdapat beberapa faktor yang berperan, baik itu faktor pendukung maupun faktor penghambat. Faktor pendukung adalah faktor yang membangun partisipasi sehingga strategi pelayanan yang ada menjadi lebih baik, sedangkan faktor penghambat adalah faktor yang menghambat suatu pelaksanan strategi pelayanan. Faktor - faktor tersebut adalah sebagai berikut: Faktor Pendukung yaitu adanya antusias pegawai dalam menjalankan strategi pelayanan dan disambut baik oleh masyarakat yang ada di kelurahan, degan membentuk TBM dan Komunitas Baca, selain itu peran aktif sekolah dalam menggiatkan siswanya melakukan peminjaman saat mobil keliling datang.

Selain itu, sarana prasana yang sudah menunjang seperti mobil untuk melakukan layanan perpustakaan keliling, pengadaan rak buku kepada komunitas pembaca masyarakat dan 100 buku dengan waktu peminjaman selama 2 bulan untuk komunitas yang desa dan kelurahan serta mengadakan sarana prasarana yang menunjang di Taman Baca Masyarakat seperti rak buku, loker, meja untuk membaca, koneksi free wifi dan AC serta koleksi refrensi yang disediakan untuk dibaca. Faktor Penghambatnya lebih kepada kurangnya kesadaran dari masyarakat untuk 
JISIP: Jurnal Ilmu Sosial dan Ilmu Politik

ISSN. 2442-6962

Vol. 9. No. 2 (2020)

membaca buku, adanya keterlambatan dalam menjalankan pelayanan dan kurangnya sumber daya manusia yang terdapat di Dinas Perpustakaan.

\section{KESIMPULAN}

Berdasarkan hasil pembahasan yang ada dapat ditarik kesimpulan bahwa masyarakat telah berperan aktif dalam mendukung strategi pelayanan Dinas Perpustakaan meliputi Layanan Perpustakaan Keliling, Layanan di Taman Bacaan Masyarakat, dan membuat Komunitas Baca. Dalam partisipasi ini di dapat beberapa faktor - faktor yang berperan dalam pelaksanaan strategi tersebut adalah adanya kerjasama yang baik antar petugas perpustakaan dan masyarakat dalam menjalankan strtaegi yang ada, serta terpenuhinya sarana dan prasarana yang ada. Namun minat baca masyarakat yang rendah menjadi faktor penghambat yang tak bisa dielakkan.

\section{DAFTAR PUSTAKA}

Mukarom, Zaenal dkk. (2015). Manajemen Pelayanan Publik. Bandung: Pustaka Setia.

Mukarom, Zaenal and Wijaya, Muhibudin (2018) Membangun Kinerja Pelayanan Publik. Bandung: CV Pustaka Setia

Fitriani, (2017). Strategi Pustakawan dalam menumbuhkan minat baca siswa di Perpustakaan SMP Negeri 4 Alla Kabupaten Enrekang. Universitas Islam Negeri Alauddin Makasar. http://repositori.uin-alauddin.ac.id (Diakses pada Tanggal 24 0ktober 2018)

Purwono, (2013). Profesi Pustakawan Menghadapi Tantangan Perubahan, Yogyakarta: Graha Ilmu.

Suharman, (2017).Strategi pelayanan di Perpustakaan dalam meningkatkan minat baca siswa di Sekolah Dasar Negeri 200 Bulue.Universitas Islam Negeri Makasar. http://repositori.uin-alauddin.ac.id (Diakses pada Tanggal 24 0ktober 2018)

Sugiyono. (2017). Metodologi Penelitian Kualitatif.dan Kuantitatif Bandung: CV. Alfabeta Zaenal Mukarom

Trihartina indah, (2013). Strategi Perpustakaan dalam meningkatkan minat baca mahasiswa pada Perpustakaan Sekolah Tinggi Ilmu Kesehatan Avicenna.

Undang-Undang Republik Indonesia Nomor 43 Tahun 2007 Tentang Perpustakaan. 